\title{
Preliminary Remarks Regarding the Prevalence of ESBL-Producing Strains of $E$. coli and $K$. Pneumoniae, Isolated from Cows with Clinical Endometritis
}

\author{
Ioana CRIVEI ${ }^{1 *}$, Andreea Paula COZMA ${ }^{1}$, Oana Alexandra $\mathrm{CIOCAN}^{1}$, Ionuț BORȘ ${ }^{2}$, Petru ROȘCA ${ }^{1}$, Dan \\ DRUGOCIU $^{1}$ \\ ${ }^{1}$ Department of Clinics, Faculty of Veterinary Medicine, M.Sadoveanu Street, No. 8, Iaşi. \\ ${ }^{2}$ Research and Development Station for Cattle Breeding Dancu - IASI SCDCB Holboca village, No. 9 Sos. \\ Iasi-Ungheni. \\ * corresponding author: ioana.crivei@yahoo.ro
}

Bulletin UASVM Veterinary Medicine 74(1) / 2017,

Print ISSN 1843-5270; Electronic ISSN 1843-5378

DOI:10.15835/buasvmcn-vm: 12502

\begin{abstract}
ESBL-producing organisms pose unique challenges to clinical microbiologists, clinicians, infection control professionals and antibacterial-discovery scientists. Although the prevalence of ESBLs is not known, it is clearly increasing, and in many parts of the world, $10-40 \%$ of strains of E. coli and K. pneumoniae express ESBLs (Rupp and Fey, 2003).

The aim of this study was to assess the prevalence of ESBL-positive strains of E. coli and K. pneumoniae in cows with clinical signs of endometritis that were treated exclusively with Oxytetracicline for both diseases of the genital area as well as other bacterial infectious diseases.

The study population included 35 Romanian Black Pied cows with clinical signs of endometritis within a farm in North Eastern of Romania. The samples were harvested using sterile cotton swabs that have been further microbiologically processed. For the phenotypic confirmation of the isolated ESBL strains, were used the combined disk test (CLSI, 2014) and the Oxoid Brilliance chromogenic ESBL Agar medium. The taxonomic classification of the isolated colonies was carried out by testing some minimal biochemical characteristics by using the MIU and TSI tests.

A total of 47 bacterial strains were isolated from uterine secretions, derived from the 35 cows included in this trial. From the total of 47 isolated bacterial strains, 17 belonged to E. coli and K. pneumoniae species, from which, 6 of them were confirmed as being ESBL-positive.

In this preliminary study, by phenotypic methods was confirmed a prevalence of $35.3 \%$ for the ESBL strains of $E$. coli and K. pneumoniae, which requires further research to confirm by molecular biology the identification of ESBL resistance genes, but also for the plasmids encoding these gene transmission.
\end{abstract}

Keywords: cows, endometritis, ESBL, Escherichia coli, Klebsiella pneumoniae.

\section{INTRODUCTION}

The increasing prevalence of antimicrobial resistant bacteria is a major concern in human and veterinary medicine. Extended-spectrum betalactamases producing Escherichia coli (ESBLsproducing $E$. coli) are the main bacterial species in which resistance is of greatest public health concern (WHO, 2011b).
Extended-spectrum beta-lactamases (ESBLs) are beta-lactamases that hydrolyses extendedspectrum cephalosporins which include cefotaxime, ceftriaxone, and ceftazidime as well as the oxyimino-monobactam aztreonam. Therefore, antibiotic options in treatment of ESBLs-producing organisms are extremely limited (Paterson, 2005). 


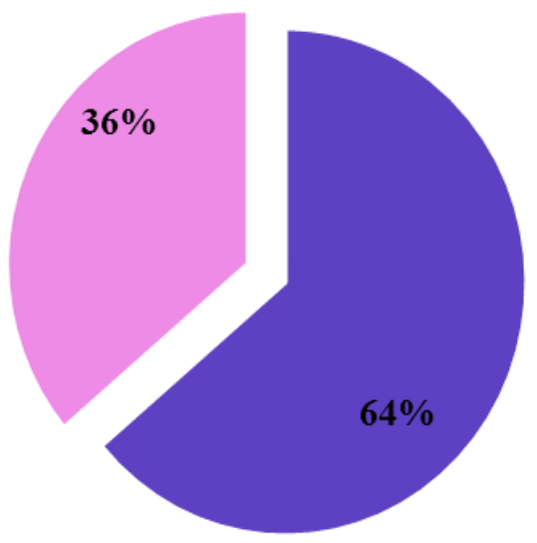

- Other bacterial strains $\quad$ Enterobacteriaceae

Fig. 1. Bacterial strains distribution by their type

For E. coli, increasing rates of resistance were recorded with respect to antimicrobials and increased resistance against the groups of third and fourth generation cephalosporins can be explained in part by the emergence of ESBLsproducing organisms (GERMAP, 2008).

In dairy cattle, antimicrobial agents are mainly used for different reasons, like respiratory, digestive and reproductive tracts infections with bacterial agents, but also to prevent diseases in healthy animals e.g. by intramammary instillation of antimicrobials in dry cows treatment (Aarestrup, 2005).

\section{MATERIALS AND METHODS}

The study was conducted in a commercial dairy farm herd located in North-Eastern of Romania. Our study population included 35 Romanian Black Pied cows with clinical signs of endometritis. All the cows selected in this study were around 7-40 days postpartum and none of the animals included in this study had received any antibiotic treatment at least one month before samples collection.

The samples were harvested using sterile cotton swabs that have been further microbiologically processed. The samples were cultured and incubated at $37^{\circ} \mathrm{C}$ for 24 hours (Măciucă, 2014). A volume of $100 \mu \mathrm{l}$ was taken from the liquid which was subsequently streaked out on the Agar Oxoid ESBL Brilliance solid chromogenic medium (Cozma, 2015). For the phenotypic confirmation of the isolated ESBL strains, we used the combined disk test (CLSI, 2014) and the Oxoid Brilliance chromogenic ESBL Agar medium.

The taxonomic classification of the isolated colonies was carried out by testing some minimal biochemical characteristics by using the MIU and TSI tests.

\section{RESULTS AND DISCUSSIONS}

Samples were collected from cows which were treated with antibiotics either in a curative or in prophylactic purpose. A total of 47 bacterial strains were isolated from uterine secretions, derived from the 35 cows included in this trial.

From the total of the isolated bacterial strains, 17 (36\%) belonged to E. coli and K. pneumoniae species (Fig. 1), and 30 (64\%) bacterial strains belonged to other bacterial species.

Out of the 17 strains of Enterobacteriaceae, 11 $(65 \%)$ of them were confirmed as being Non-ESBL and $6(35 \%)$ were identified as ESBL- producing strains. Thus, from the total of 6 ESBL-producing strains, 5 (29\%) were identified as Escherichia coli and $1(6 \%)$ was identified as Klebsiella pneumoniae (Fig. 2).

The emergence of bacterial strains resistant to antibiotics is supported by irrational or repeatedly administration of the same antibiotic, that leads in time to the occurrence of this phenomenon. Isolation and confirmation of ESBL strains has important connotations, both for the farmers as well as for public health.

The high costs imposed by the treatment of bacterial infections caused by strains resistant 


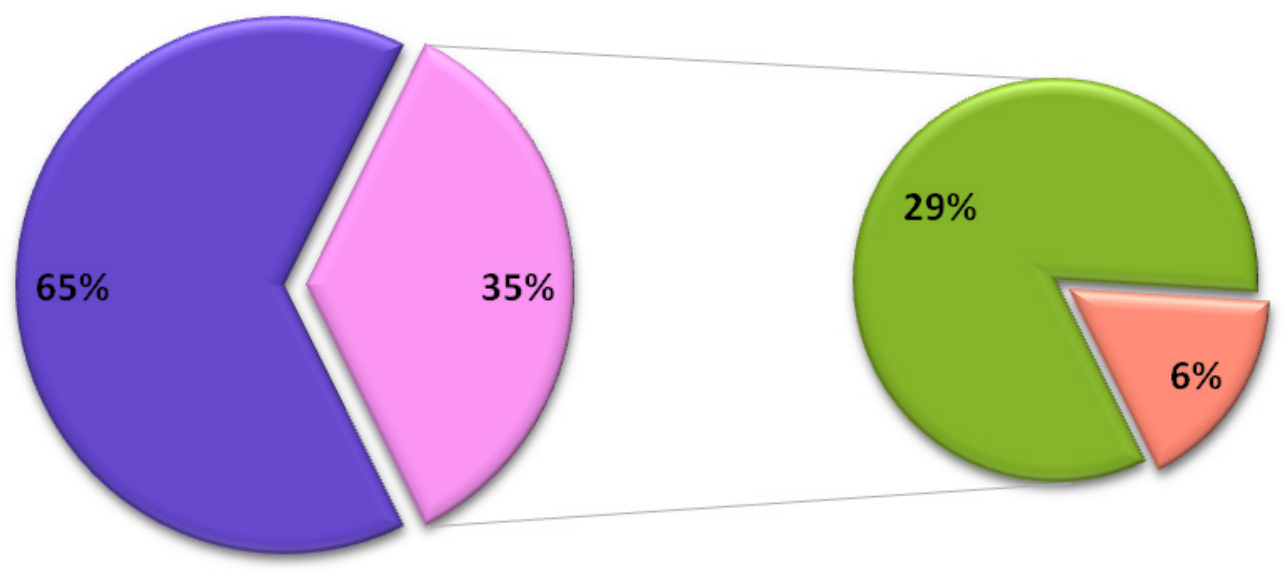

$\square$ Non-ESBL $\square$ Escherichia coli $\square$ Klebsiella pneumoniae

Fig. 2. Enterobacteriaceae distribution based on their resistance profile

to antibiotics and the waiting time for disposing the administered antibiotic, brings significant losses for farmers, therefore the production costs are increasing. Also, in cross transmission of these bacterial strains affects human health by transmitting of these resistance genes in both directions, human - animal - human, both through direct contact and indirectly.

Taking into consideration our results, we can hypothesize that the irresponsible usage of the antibiotics to treat lameness, dystocia or endometritis in cows, may be associated with the detection of ESBL-producing E. coli, in treated animals, which indicates that further studies are necessary to establish if the use of antibiotics in cows treatment with different diseases or health problems is also associated with the detection of ESBL-producing E.coli into farm's bulk milk tank.

\section{CONCLUSIONS}

From the total of 35 cows diagnosed with endometritis included in this preliminary study, we confirmed by phenotypic methods a prevalence of $36 \%$ for the ESBL strains of $E$. coli and $K$. pneumoniae, which requires further research to confirm by molecular biology the identification of ESBL resistance genes, but also for the plasmids encoding these gene transmission.

\section{REFERENCES}

1. Aarestrup FM (2005). Veterinary drug usage and Antimicrobial Resistance in Bacteria of Animal Origin; Pharmacology Toxicology, Vol. 96, Issue 4( 271-281).

2. Clinical and Laboratory Standards Institute (CLSI), (2014). Performance Standards for Antimicrobial Susceptibility Testing.

3. Cozma A, Carp Cărare C, Porea D, Guguianu E, Rîmbu C, Mareș M, Carp Cărare M (2015). The prevalence of ESBL-producing strains of $E$. coli and $K$. pneumoniae, isolated from pets treated with antibiotics, Bulletin of University of Agricultural Sciences and Veterinary Medicine Cluj-Napoca, Vol. 72 (2).

4. German Network of Antimicrobial Resistance Surveillance (GERMAP), (2008). Antibiotika Resistenz und -Verbrauch: Bericht über den Antibiotika verbrauch und die Verbreitung von Antibiotikaresistenzen in der Human- und Veterinärmedizin in Deutschland.

5. Paterson DL, Bonomo RA (2005). Extended-Spectrum $\beta$-Lactamases: a Clinical Update. Clinical Microbiology Reviews, 18 (4), 657-686.

6. Rupp ME, Fey PD (2003). Extended spectrum $\beta$-lactamase (ESBL)-producing Enterobacteriaceae. Drugs, 63 (4), 353365.

7. World Health Organization (WHO), (2011). Public Health Importance of Antimicrobial Resistance. See: http:// www.who.int/drugresistance/AMR_Importance/en/ index.html 